\title{
TOMÁS DE AQUINO E A ESSÊNCIA ABSOLUTAMENTE CONSIDERADA
}

\author{
Marco Aurélio Oliveira da Silva* \\ silva.marco@ufba.br
}

RESUMO O presente artigo propõe uma interpretação deflacionista para a doutrina da essência absolutamente considerada (EAC), apresentada por Tomás de Aquino no opúsculo "De ente et essentia". O norte do trabalho é a análise das expressões reduplicativas que são constantemente utilizadas pelo Doutor Angélico para designar as EAC's. Portanto, pretendo mostrar que a EAC é a consideração dos predicados essenciais, que se predicam das expressões reduplicadas, diferentemente da noção acidental de existência. Por isso, a EAC não existe nem no intelecto nem na realidade, o que, dito em outras palavras, significa apenas que "existir no intelecto" e "existir na realidade" são predicados acidentais em relação às essências apreendidas abstrativamente pela mente.

Palavras-chave Tomás de Aquino, Reduplicação, Essência Absolutamente Considerada.

ABSTRACT This paper proposes a deflationist interpretation of the doctrine of the Nature as such, which Thomas Aquinas exposes in his work "De ente et essentia". The aim of this paper is to provide an analysis of reduplicative expressions used by Aquinas to refer nature as such. Hence, I will show that the nature as such is the consideration of the essential properties predicated by the reduplicative expressions, diverse from the accidental notion of 'existence'. Consequently, nature as such does not exist in the intellect and 
do not exist in reality, for in other words 'existing in the intellect' and 'existing in the reality' are accidental predicates when attributed to essences grasped by the mind.

Keywords Thomas Aquinas, Reduplicative Expressions, Nature as Such.

A solução de Tomás de Aquino ao problema dos universais supõe que a universalidade propriamente dita é uma intenção lógica emprestada pelo intelecto a uma essência apreendida abstrativamente. A consideração da essência, deixando de lado se ela existe universalizada na mente ou individualizada na realidade, implica a admissão de uma Essência Absolutamente Considerada (EAC). Nesse sentido, Tomás de Aquino afirma:

[...] a natureza do homem, absolutamente considerada, abstrai de qualquer ser (esse), de tal modo, porém, que não haja exclusão (praecisio) de nenhum deles. ${ }^{1}$ (Tomás de Aquino, "De ente et essentia", Cap. 3. Ed. Leonina, 1976, p. 374 ${ }^{67-69}$. ed. bras., 1995, p. 32)

Ou seja, considerar uma essência absolutamente significa considerá-la segundo seus aspectos definicionais, independentemente de características acidentais. Desse modo, tanto a existência intencional da espécie quanto a existência concreta do indivíduo sensível não podem ser consideradas como essenciais.

A literatura teve alguma dificuldade em explicar o que seria essa EAC. Sandra Edwards (2002, p. 98), por exemplo, considera-a como um quarto modo de existência da essência, ao lado da existência ante rem, na mente de Deus, da existência in re, na coisa, e da existência post rem, no intelecto humano. A dificuldade desta tese de Edwards é o fato de introduzir a EAC como uma entidade distinta da natureza existente na mente e na realidade, sendo, a meu ver, uma introdução desnecessária de platonismo na ontologia de Tomás.

Nesse sentido, proponho uma interpretação mais reducionista, considerando as referências à EAC em conexão com a noção de proposição reduplicativa, uma vez que tanto na explicação da noção de EAC quanto na referência a nomes abstratos (humanidade, por exemplo), Tomás recorre

1 "Ergo patet quod natura hominis absolute considerata abstraihit a quolibet esse, ita tamen quod non fiat praecisio alicuius eorum". 
invariavelmente a expressões reduplicativas. Portanto, a EAC seria um modo de considerar abstratamente uma essência, levando em consideração apenas seus aspectos definicionais, deixando de lado o que é próprio a um modo de existência da essência, seja na coisa, seja no intelecto.

\section{Essência Absolutamente Considerada e proposições reduplicativas}

A discussão técnica de Tomás de Aquino sobre as proposições reduplicativas encontra-se, principalmente, em textos com o fim de explicar o mistério da Encarnação, como o "Comentário ao Livro das Sentenças de Pedro Lombardo" ("Scriptum super libros Sententiarum", lib. 3, d. 11 q. 1 a. $3)^{2}$, texto datado entre 1252 e 1254, anterior ou pelo menos contemporâneo ao "De ente et essentia", datado entre 1252 e $1256^{3}$. Naquele texto, Tomás de Aquino afirma:

Mas, predicado essencial pode ser predicado de qualquer sujeito com reduplicação, assim como em "Sócrates enquanto é homem é animal", porque animal predica-se per se de homem. (Tomás de Aquino, "Scriptum super libros Sententiarum", lib. 3, d.10, q.1, a.1, qc. 2 , s.c. 1$)^{4}$

Proposições reduplicativas, tais quais entendidas por Tomás de Aquino, são proposições nas quais um termo é repetido através de expressões próprias, como "enquanto", "na medida em que", "pelo fato de ser", etc. No caso da citação, o uso de um nome próprio pode confundir a consideração da reduplicação em Tomás como a repetição de um termo, mas devemos observar que, para o filósofo escolástico, nomes próprios sempre abreviam um termo geral antecedido pelo demonstrativo "este". Portanto, o nome próprio "Sócrates" abrevia a expressão "este homem”. Uma defesa desta tese sobre os nomes próprios em Tomás pode ser observada no seguinte texto:

Conhece-se, com efeito, Cálias não apenas enquanto é Cálias, mas também enquanto é este homem, e do mesmo modo, [conhece-se] Sócrates na medida em que é este homem. (Tomás de Aquino, "Expositio libri Posteriorum", lib. II, lect. 20, § 14. Ed. Leonina, 1882, p. 402b)

2 O título do artigo referido é "Se Cristo enquanto homem é uma criatura?".

3 Com relação à datação da obra de Tomás de Aquino, cf. Torrell, 1999.

4 "Sed praedicatum essentiale potest praedicari de subjecto quocumque cum reduplicatione, sicut Socrates in quantum est homo, est animal: quia animal per se de homine praedicatur" (tradução própria).

5 "Cognoscit enim calliam non solum in quantum est callias, sed etiam in quantum est hic homo, et similiter socratem in quantum est hic homo" (tradução própria). 
Portanto, a proposição "Sócrates enquanto homem é racional" é reduplicativa, pois é equivalente à proposição "Este homem enquanto homem é racional".

A relação entre reduplicação e predicação essencial (per se) pode ser observada no intérprete Tomás de Vio Caetano, que no século XVI comenta o "De ente et essentia" do seguinte modo:

Pois, embora no caso de uma proposição afirmativa com predicado infinito, quando as proposições não são reduplicadas, segue-se a proposição negativa correspondente, e vice-versa, como foi dito no "Perihermeneias" II; contudo, quando há reduplicação, mesmo de uma proposição afirmativa com predicado infinito segue-se uma proposição negativa com predicado finito, embora não ocorra o oposto. Da proposição "homem porque é homem não é branco" não se segue "homem porque é homem é não-branco". Pois, se homem fosse não-branco pelo fato de ser homem, então a brancura nunca poderia ocorrer a um homem, pois o que pertence a algo, na medida em que é este algo, ocorre sempre de modo necessário e per se. (Caetano, "Commentarium super Opusculum De Ente et Essentia Thomae Aquinatis", p. 97. Tradução inglesa, 1964, p. 164. $)^{6}$

Esta citação de Caetano interessa menos como explicação do texto de Tomás, mas interessa mais por expressar como a recepção de Tomás de Aquino avaliava a necessidade de se compreender a reduplicação para uma compreensão adequada da doutrina apresentada no "De ente et essentia". O comentário de Caetano foi escrito para rebater as teses scotistas em voga no final da Escolástica, contudo, devemos analisar se a teoria de Tomás de Aquino é compatível com duas teses sintetizadas nesta citação de Caetano. Em primeiro lugar, é necessário saber se a teoria de Tomás é compatível com a tese segundo a qual uma proposição reduplicada negativa com predicado finito (S enquanto $\mathrm{S}$ não é $\mathrm{P}$ ) não implica a correspondente proposição reduplicada afirmativa com predicado infinito ( $\mathrm{S}$ enquanto $\mathrm{S}$ é não $\mathrm{P})^{7}$. Em segundo lugar, é preciso saber se, assim como sugerido por Caetano, a proposição reduplicativa tem a

6 "Licet enim ex affirmativa de praedicato infinito sequatur negativa, et e converso, ut dicitur in II Perihermenias, quando non sunt reduplicativae; cum reduplicatione tamen licet ex affirmativa de praedicato infinito, sequatur negativa se praedicato finito, non tamen e contra. Hanc enim, Homo in eo quod homo non est albus, non sequitur ista, Homo in eo quod homo est non albus. Si enim homo in eo quod homo esset non albus, numquam homini coniungi posset albedo: quia quod convenit alicui, secundum quod ipsum, convenit ei semper necessario et per se" (tradução própria).

7 Alan Bäck (1996, p. 481) considera esta peculiaridade sobre as proposições negativas como uma criação pós-escolástica. Contudo, pretendo demonstrar que esta compreensão auxilia na explicação da própria letra de Tomás, explicitando a relação entre valor de verdade e proposições reduplicativas essenciais. Embora eu conceda que a consideração desta contraposição como uma distinção de forma lógica não ocorra em Tomás de Aquino, podemos observá-la como uma distinção em termos meramente gramaticais que permite compreender melhor as considerações que o Aquinate faz no "De ente et essentia" sobre as essências absolutamente consideradas. 
função de distinguir predicados necessários de predicados acidentais, o que seria uma típica consideração de modalidade de re.

Contudo, uma questão que tem preocupado a interpretação contemporânea do uso das proposições reduplicativas na Escolástica consiste na dificuldade de se determinar a forma lógica delas, de modo que a proposição reduplicativa não seja redutível à proposição universal equivalente, como nas proposições "homem enquanto homem é racional" e "todo homem é racional". Há uma compreensão intuitiva de que a primeira proposição expressa algo mais do que uma mera predicação extensional.

\section{Proposição reduplicativa: forma lógica ou estrutura gramatical?}

O locus clássico do problema da proposição reduplicativa encontra-se em Aristóteles nos "Primeiros Analíticos", I. 38, no qual o estagirita explica a forma de silogismos contendo proposições com qualificativo. ${ }^{8}$ Contudo, o desenvolvimento da lógica clássica aristotélica, ao longo da História da Filosofia Medieval, não se centrará apenas na explicação da relação entre a cláusula reduplicativa ("enquanto homem", por exemplo, na proposição "homem enquanto homem é racional") e a figura do silogismo."

No caso das proposições reduplicadas, nas quais o mesmo termo consta como extremo do silogismo e como o termo que segue a cláusula de reduplicação (por exemplo, "homem enquanto homem", "homem na medida em que é homem", "homem pelo fato de ser homem", e assim por diante), há uma predicação per se, ou seja, uma predicação essencial. Contudo, como determinar a sua forma lógica, de modo que a proposição reduplicativa essencial não seja redutível à proposição universal equivalente?

Observe-se a interpretação da forma lógica das proposições com qualificativos, tanto acidentais quanto essenciais, sugerida por Bäck: " $S$ é $\mathrm{P}$

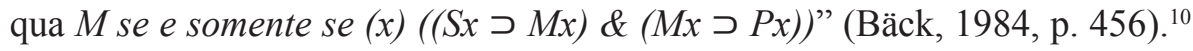

8 Cf. Aristóteles, "Analytica Priora", 49a11-16; Bäck, 1982. Como a principal intenção de Aristóteles é explicar a silogística, ele deixa claro que a expressão responsável pela reduplicação deve estar conectada ao primeiro extremo do silogismo, nunca ao termo médio. A razão é simples, se estivesse conectado ao termo médio, a expressão reduplicada não ocorreria na conclusão.

9 Allan Bäck (1982, p. 454) apresenta uma explicação bastante clara do referido trecho de Aristóteles:

"Todo M é $\mathrm{P}$ qua $\mathrm{M}$

O bom é conhecido, na medida em que é bom

Todo S é M

Justiça é boa

Logo, todo S é P qua M

Justiça é conhecida, na medida em que é boa".

10 Posições semelhantes, ressaltando uma interpretação extensional, podem ser observadas também nos seguintes trabalhos: Angelelli, 1978; Casanave et al., 2008. Bäck, ao explicar de forma lógica essas proposições, tenta englobar tanto proposições reduplicativas essenciais como as qualificativas com predicado acidental, como "o Etíope é branco quanto ao dente". Ele assim o faz pelo fato de o termo 
Ou seja, nesta interpretação, a proposição reduplicativa seria apenas um silogismo condensado, no qual o termo reduplicado faria as vezes de termo médio. Contudo, esta interpretação omite um dado fundamental da proposição reduplicativa, a saber, o caráter modal do predicado da proposição. Ou seja, uma proposição reduplicada, além de condensar duas proposições universais, toma essencialmente o respectivo predicado.

Para efeito de ilustração, consideremos os seguintes exemplos:

- "Homem é racional enquanto homem";

- "Homem nasce no planeta Terra enquanto homem".

Sabemos intuitivamente que a racionalidade está de tal forma conectada com a humanidade que repugna ao intelecto admitir um homem que seja irracional. Em contrapartida, a consideração contrafactual de um homem que nasça em uma estação espacial prima facie não contraria a definição de homem. E eis o ponto central. Uma proposição reduplicativa tem o papel de distinguir propriedades que estão contidas na definição, sejam elementos da definição (gênero ou diferença específica) ou mesmo um próprio. Excluem-se, neste caso, os acidentes.

Portanto, faz-se necessário admitir mais um elemento para explicitar a forma lógica da proposição reduplicada. Portanto, seguindo Polli, podemos admitir, além da caracterização extensional, uma consideração que remeta à predicação essencial, a saber:

[...] podemos dizer que a análise formal decompõe a expressão reduplicativa em:

(i) A é B.

(ii) Todo B é C.

(iii) B é a razão pela qual A é C. (Polli, 1994, p. 93)

Nesta análise, podemos observar um descompasso entre os passos (i) e (ii) em contraposição ao passo (iii). O primeiro par de critérios trata de predicação extensional de primeira ordem, o que se trata de algo extremamente compreensível, embora insuficiente para distinguir a proposição reduplicativa da equivalente universal. A cláusula (iii) apresenta uma predicação de segunda ordem, com a relação "ser razão de" sendo predicada da propriedade "B" e da proposição "A é C", que estão na posição de sujeitos da relação. Embora

\footnotetext{
"reduplicativo" possuir vários empregos ao longo da história do desenvolvimento da lógica aristotélica. Embora Tomás de Aquino utilize o termo para significar estritamente a cláusula repetitiva - no que é seguido por Caetano -, e, portanto, essenciais, Bäck, em contrapartida, o utiliza em um sentido mais amplo, para englobar também as proposições qualificativas de predicação acidental. Por esta feita, Bäck propõe uma forma lógica mais restritiva para proposições com qualificativo e predicação essencial, a

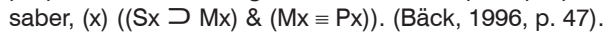


haja esta dificuldade quanto à formalização proposta, poderemos observar adiante que essa cláusula (c) permitirá explicar um fenômeno fundamental para a nossa explicação da modalidade de re em Tomás de Aquino, seguindo o fenômeno linguístico apresentado por Caetano, a saber, a disparidade entre uma proposição reduplicada negativa e a equivalente proposição infinita.

Para compreender por que isso ocorre, devemos remontar à análise de Poli acima acerca da forma lógica de proposições reduplicativas. Considerando-se os três termos da proposição reduplicada " $S$ é P qua M", ou seja,

a) $(\mathrm{x})(\mathrm{Sx} \supset \mathrm{Mx}) \&$

b) $(\mathrm{x})(\mathrm{Mx} \supset \mathrm{Px}) \&$

c) A propriedade B é a razão (causa formal) da proposição (x) (Sx つ Px).

Podemos observar ademais que da conjunção de (a) e (b) segue-se:

d) $(\mathrm{x})(\mathrm{Sx} \supset \mathrm{Px})$

Ora, observe-se que o passo (c) estabelece uma relação intencional entre as propriedades $\mathrm{S}, \mathrm{M}$, e $\mathrm{P}$, ao passo que a proposição (d) trata das mesmas propriedades, só que do ponto de vista extensional. Portanto, (c) implica (d), de modo que, se se nega (d), ter-se-á que negar (c). Ou seja, a negação de (a) implica a negação de (c), e a negação de (b) também implica a negação de (c).

Se admitíssemos apenas a interpretação extensional da proposição reduplicativa, não faria sentido distinguir proposições negativas de infinitas, elas seriam equivalentes. Contudo, é com o passo (c) que vemos uma mudança ocorrer.

Quando eu afirmo que "S não é P qua M", a proposição (c) deve ser reescrita assim:

c') A propriedade M não é a razão da proposição (x) (Sx つ Px).

Ou seja, eu nego a relação "ser razão de". Em contrapartida, quando eu afirmo a equivalente infinita "S é não P qua M", a proposição (c) deve ser reescrita assim:

(c) A propriedade M é a razão da negação da proposição (x) (Sx つ Px).

Reconstruindo a proposição reduplicativa com o auxílio desta predicação relacional de segunda ordem, fica clara a distinção entre as formas gramaticais infinita e negativa do reduplicativo. Ou seja, não há aqui uma objeção à tese de que formas proposicionais infinitas e negativas devam ter o mesmo valor de verdade. Ocorre apenas que, embaixo da forma gramatical aparentemente monádica das proposições reduplicativas, existe uma estrutura relacional, o 
que explica este fenômeno controverso da linguagem natural, segundo o qual parecia haver um contraexemplo para a identidade de valor de verdade entre proposições infinitas e correspondentes negativas.

Contudo, estas três formas gramaticais das proposições reduplicativas (afirmativa, negativa e infinita) terão um papel central na explicação da EAC em Tomás de Aquino apresentada aqui, no que tange a um tratamento reducionista da Essência Absolutamente Considerada.

\section{Predicação essencial $X$ acidental em Tomás de Aquino}

Ao tratar da Essência ou Natureza considerada de modo absoluto (EAC), devemos observar duas características fundamentais: a) só se predicado verdadeiramente da EAC o que lhe convém enquanto tal "convenit sibi secundum quod huisusmodi" (Tomás de Aquino, "De ente et essentia", Cap. 3. Ed. Leonina, 1976, p. $374^{26-30}$. Ed. bras., 1995, p. 30); ${ }^{11}$ b) o que não the convier enquanto tal é falso. Podemos destacar, portanto, a referência a uma expressão reduplicativa típica (secundum quod) e a referência ao valor de verdade de uma determinada predicação.

Ora, a essência é uma entidade real que existe nas coisas no mundo, designada por sua vez através de nomes da linguagem ordinária. Considerar uma natureza de modo absoluto, do ponto de vista linguístico, importa o recurso à reduplicação. Neste sentido, embora se possa afirmar que "há homens brancos", "alguns homens são calvos", etc., para se referir ao conteúdo definicional (ratio propria), faz-se mister recorrer à reduplicação do termo que designa uma determinada essência. Portanto, nesse caso, referirnos-íamos a "homem enquanto homem é x". Se no lugar da variável "x" estiver um elemento definicional ou uma propriedade essencial ("racional", por exemplo), então a predicação será verdadeira. Em contrapartida, o recurso a uma propriedade acidental ("branco", por exemplo), ou mesmo a uma propriedade não instanciada pelo conceito homem ("alado", por exemplo), resultaria uma predicação falsa.

A caracterização da essência absolutamente considerada como independente, quer da existência mental, quer da existência real, pode ser observada a partir da consideração de expressões reduplicativas. Nesse sentido, Tomás de Aquino afirma o seguinte:

11 "Natura autem uel essentia sic accepta potest dupliciter considerari. Vno modo secundum rationem propriam, et haec est absoluta consideratio ipsius : et hoc modo nichil est uerum de ea nisi quod conuenit sibi secundum quod huiusmodi ; unde quicquid aliorum attribuatur sibi, falsa est attributio. Verbi gratia, homini in eo quod homo est convenit rationale et animal et alia quae in diffinitione eius cadunt." 
É considerada [a essência] de outro modo, de acordo com o ser que tem nisto ou naquilo. Deste modo, algo predica-se dela por acidente em razão daquilo em que é, assim como se diz que o homem é branco, porque Sócrates é branco, embora isto não caiba ao homem por ser homem. (Idem, p. 374 ${ }^{45-51}$. Ed. bras., 1995, p. 31) ${ }^{12}$

Ou seja, a afirmação "um homem é branco" não decorre das considerações definicionais, mas da existência individual de algo que é homem e que é branco. Ao recorrermos ao reduplicativo, devemos observar que a "existência" comporta-se como o predicado "branco", pois não convém ao homem enquanto homem existir no intelecto e também não convém existir na realidade. Pois a existência não está contida no conteúdo definicional (ratio propria) de homem.

A resposta tomásica ao problema da dupla natureza da EAC consiste em considerar que multiplicidade e unicidade são acidentes da EAC. Ora, dado que unidade e multiplicidade são acidentais em relação à EAC, seguese que universalidade é acidental em relação a este modo de considerar a essência, pois o conceito de universalidade envolve os conceitos de unicidade e multiplicidade - o que (é uno e) está em muitos. Ou seja, a aplicação pelo intelecto da intenção de universalidade a uma determinada essência só é possível porque tanto unidade quanto multiplicidade são predicados acidentais em relação à EAC.

Nesse sentido, Tomás de Aquino afirma que "é verdadeiro dizer que o homem, não na medida em que é homem, obtém o ser neste singular ou naquele ou na alma" (Cf. Idem, p. $374^{66-67}$. Ed. bras., 1995, p. 32). ${ }^{13}$ Ou seja, ser singular na realidade ou universal na mente não se seguem da essência considerada de modo absoluto, o que poderia ser reescrito assim: "homem enquanto homem não é singular na realidade" e "homem enquanto homem não é universal na mente", tomando nesta citação do "De ente et essentia" a explicação da predicação acidental pela forma gramatical negativa do reduplicativo. Daí não se segue as formas correspondentes infinitas: "homem enquanto homem é algo não singular" e "homem enquanto homem é algo não universal". Observe-se que o objeto de Tomás é apenas distinguir propriedades essenciais (que se predicam com verdade da expressão reduplicada, ou seja, repetida) de propriedades acidentais.

12 "Alio modo consideratur secundum esse quod habet in hoc vel in illo, et sic de ipsa aliquid praedicatur per accidens ratione eius, in quo est, sicut dicitur quod homo est albus, quia Socrates est albus, quamvis hoc non conveniat homini in eo quod homo."

13 "[...] homo, non in quantum est homo, habet quod sit in hoc singulari vel in illo aut in anima." 
Portanto, não há qualquer contradição em se afirmar que a EAC não é nem una nem múltipla, como não há contradição em afirmar que o homem absolutamente considerado (homem enquanto homem) não é nem branco nem não branco, o que se segue de (i) "homem enquanto homem não é branco" e (ii) "homem enquanto homem não é não branco"; contudo, estas - pela admissão da disparidade entre formas gramaticais reduplicativas negativas e infinitas - não implicam nem (i') "homem enquanto homem é não branco" e (ii') "homem enquanto homem é branco". Portanto, a distinção gramatical assinalada é fundamental para compreender a EAC como um modo abstrativo de se compreender algo, com o fim de distinguir propriedades essenciais de propriedades acidentais.

Desse modo, a essência considerada em si mesma não é nem particular nem universal. ${ }^{14}$ Apenas na medida em que existe de algum modo, a essência será particular ou universal. Ora, será particular quando tiver uma existência nos indivíduos e, portanto, independente do intelecto. Em contrapartida, será universal quando existir no intelecto. A unicidade, a multiplicidade e a universalidade seguem-se do modo de existência de um ente, e não de sua EAC. ${ }^{15}$ Desse modo, unicidade, multiplicidade, universalidade e singularidade são características não definicionais das essências de um modo geral e, portanto, não pertencem às essências quando consideradas de modo absoluto.

Portanto, uma compreensão adequada da estrutura das proposições e expressões reduplicativas - o que estaria na formação de qualquer estudante escolástico de Lógica - leva-nos a concluir que S. Edwards não poderia ter admitido um quarto tipo de essência. Pois, assim como admitir um triângulo, sem considerar se é escaleno, equilátero ou isósceles, não nos obriga a admitir um quarto tipo de triângulo, assim também considerar uma essência, sem considerar se ela existe na mente de Deus, nas coisas ou no intelecto, não nos obriga a admitir um quarto tipo de essência. ${ }^{16}$

\section{Referências}

ANGELELLI, I. “Analytica Priora I, 38 and Reduplication". Notre Dame Journal of Formal Logic, Vol. 19, Nr. 2, pp. 295-296, 1978.

14 Cf. Galluzzo, 2004, p. 158.

15 Cf. Owens, 1961, p. 241; Inagaki, 1967, p. 182.

16 Versões preliminares do presente trabalho foram apresentadas no Grupo de Estudo e Pesquisa Empiricismo, Fenomenologia e Gramática (UFBA), no XVII Congresso da Sociedade Interamericana de Filosofia (SIF 2013, Salvador) e no Programa de Pós-Graduação em Lógica e Metafísica da UFRJ. Agradeço a inúmeras contribuições recebidas, entre as quais vale ressaltar as de Alfredo Storck, Carlos Eduardo Oliveira, Edgar Marques, João Carlos Salles, Markos Klemz e Rodrigo Guerizoli. 
ARISTOTLE. "Prior Analitics (Analytica Priora)". In: J. Barnes (Ed.), 1984. pp. 39113.

BÄCK, A. "On Reduplication: Logical Theories of Qualification”. Leiden: E. J. Brill, 1996.

BÄCK, A. "Syllogisms with Reduplication in Aristotle". Notre Dame Journal of Formal Logic, Vol. 23, Nr. 4, pp. 453-458, 1982.

BARNES, J. (ed.) "The complete works of Aristotle". Translated by A. J. Jenkinson. Oxford: Princeton University Press, 1984.

CAETANO. (Caetan) "Commentary on Being and Essence". Translated by Lottie H. Kendzierski \& Francis C. Wade. Milwakee: Marquete Universiy Press, 1964.

CAETANO. (Thomae de Vio Caetani) "Commentarium super Opusculum De Ente et Essentia Thomae Aquinatis". Romae: Ex Pontificia Officina Typographica, 1907.

CASANAVE, A. et al. "Abstração como operação lógica em Aristóteles". O Que nos Faz Pensar (PUCRJ), Vol. 24, pp. 205-210, 2008.

DAVIES, B. (ed.). "Thomas Aquinas. Contemporary philosophical perspectives". Oxford: Oxford University Press, 2002.

EDWARDS, S. “The Realism of Aquinas". In: B. Davies (Ed.). 2002. pp. 97-115.

GALLUZZO, G. "Aquinas on Common Nature and Universals". Recherches de Théologie et Philosophie Médiévales, Vol. 71, pp. 131-171, 2004.

INAGAKI, B. R. "Thomas Aquinas and the Problem of Universals: A ReExamination". Studies in Philosophy and the History of Philosophy, Vol. 4, pp. 174190, 1967.

OWENS, J. "Unity and Essence in St. Thomas Aquinas". Mediaeval Studies, Vol. 23, pp. 240-259, 1961.

POLI, R. "Formal Aspects of Reduplication". Logic and Logical Philosophy, Vol. 2, pp. 87-102, 1994.

SILVA, M. A. O (ed.). "Linguagem e Verdade na Filosofia Medieval". Salvador: Quarteto, 2013.

SILVA, M. A. O. "Essência e reduplicação em Tomás de Aquino". In: M. A. O. Silva (Ed.). 2013. pp. 109-125.

TOMÁS DE AQUINO. "O ente e a essência". Tradução de Carlos Arthur R. do Nascimento. Petrópolis: Vozes, 1995.

TOMÁS DE AQUINO. "De ente et essentia". In: Sancti Thomae de Aquino Opera omnia iussu impensaque Leonis XIII P. M. edita, t. 43. Roma: Editori di San Tommaso, 1976. pp. 315-381.

TOMÁS DE AQUINO. "Scriptum super libros Sententiarum". 3. ed. M. F. Moos. Paris: Lethielleux, 1933.

TOMÁS DE AQUINO. "Expositio libri Posteriorum". In: Sancti Thomae de Aquino Opera omnia iussu impensaque Leonis XIII P. M. edita, t. 1 */2. Roma: Ex Typographia Polyglotta S. C. de Propaganda Fide, 1882.

TORRELL, J.-P. "Iniciação a Santo Tomás de Aquino". Tradução de Luiz Paulo Rouanet. 2. ed. São Paulo: Loyola, 1999. 